\title{
Perancangan Keamanan Server Linux Dengan Metode Hardening Pada Layer 1 dan Layer 7
}

\author{
Maraghi Agil Prabowo*, Ucuk Darusalam, Sari Ningsih \\ Fakultas Teknologi Komunikasi dan Informatika, Teknik Informatika, Universitas Nasional, Indonesia \\ Email: 1," agilprab@gmail.com, ${ }^{2}$ ucuk.darusalam@gmail.com, ${ }^{3}$ sariningsih.lectures@ yahoo.com \\ Email Penulis Korespondensi: agilprab@gmail.com
}

\begin{abstract}
Abstrak-Banyak pihak ataupun lembaga yang masih tidak menyadari keamanan pada sebuah server, tidak hanya bergantung pada aplikasi IDS dan IPS serta beberapa apliksi firewall yang dapat dengan mudah kita temukan melalui jejaring internet. Dibutuhkan juga penanganan keamanan khusus pada server-server yang tidak terkait dengan apliksi pihak ketiga. Perancangan keamanan tersebut dapat diterapkan melalui konfigurasi kernel serta tweak yang dapat dilakukan dengan mengandalkan aplikasi bawaan sebuah sistem operasi. Aplikasi tersebut sangat umum dan dapat ditemukan dihampir seluruh jenis distro linux server. Serta masih banyak orang yg tidak memaksimalkan keamanan yang disediakan oleh BIOS (Basic Input Output System) sehingga sistem operasi yang sudah terinstal serta data-data yang tersimpan didalamnya dapat dengan mudah diakes oleh pihakpihak yang tidak bertanggungjawab. Kemudian sebagai langkah pencegahan agar data-data yang tersimpan tidak dapat diakses sembarangan oleh orang-orang yang tidak bertanggung jawab, disediakan enkripsi serta pembagian file sistem yang akan diinstal di server tersebut. Dalam langkah pengamanan akses akun, kata sandi yang dibuat akan diberi masa kadaluarsa serta penggua tidak dapat menggunakan kata sandi lama yang pernah Ia gunakan sebelumnya.
\end{abstract}

Kata Kunci: Server, Hardening, Layer OSI, Linux Server, Server Security

\begin{abstract}
Many person or institutions are still not aware of security on a server, not only rely on IDS and IPS applications and some firewall applications that we can easily find through internet networks. Special security handling is required on servers that are not related to third-party applications. The security design can be implemented through kernel configuration and tweaks that can be done by relying on the default application of an operating system. These applications are very common and can be found in almost all types of Linux server distributions. And there are still many people who do not maximize the security provided by the BIOS (Basic Input Output System) so that the operating system that has been installed and the data stored therein can be easily accessed by parties who are not responsible. Than as a preventive measure so that the data stored can not be accessed haphazardly by people who are not responsible, provided encryption and the sharing of system files that will be installed on the server. In the security steps for account access, the password that is created will be expired and the user cannot use the old password that he has used before.
\end{abstract}

Keywords: Server, Hardening, Layer OSI, Linux Server, Server Security

\section{PENDAHULUAN}

Kemajuan teknologi di bidang jaringan telah memungkinkan untuk melakukan interaksi melalui komputer. Jaringan komputer adalah sekumpulan peralatan komputer yang dihubungkan agar dapat saling berkomunikasi dengan tujuan membagi sumber daya. Dalam sebuah jaringan komputer dibutuhkan aturan-aturan (protocols) yang mengatur komunikasi dan layanan-layanan secara umum untuk seluruh sistem jaringan.[1]

Jaringan komputer memiliki fungsi yang boleh dibilang cukup vital dalam teknologi informasi. Pada jaringan komputer maka diperlukanlah sebuah sistem keamanan server untuk melindungi komputer server dari ancaman baik dalam bentuk kesengajaan ataupun bukan. [2] Suatu jaringan komputer terdiri dari server dan client. Server sendiri biasanya dikendalikan oleh seorang administrator, baik monitoring secara langsung maupun dengan cara di remote. Administrator yang mengkontrol suatu server haruslah orang yang sudah kompeten dalam bidangnya. Karena saat ini banyak sekali pelaku kriminal dalam dunia cyber yang dengan sengaja masuk kedalam sistem dan kemudian melakukan perubahan serta merusak berbagai konfgurasi server hanya untuk kesenangan semata atau bahkan mengambil keuntungan materil. Berikut ini jenis-jenis serangan mendasar yang sering terjadi pada jaringan, antara lain IP Spoofing/Session Hijacking, Packet Snifer, DDoS, Man-in-the Middle, Back Door. [1] Untuk itu keamanan dalam sebuah server sangatlah diperlukan. Keamanan pada server sendiri berkaitan dengan berbagai lapisan-lapisan penunjang sistem keamanan, atau layer OSI.

The Open System Interconnection (OSI) atau yang biasa disebut dengan layer OSI merupakan suatu susunan jaringan yang di implementasikan melalui protokol jaringan ke dalam tujuh lapisan berbeda. Lapisan-lapisan pada Layer OSI dibuat dengan tujuan agar setiap paket data dalam sebuah jaringan dapat melewati satu per satu layer yang pada akhirnya bisa saling terkoneksi.[1]

Cara kerja dari OSI Layer sendiri adalah proses berjalannya suatu data dari suatu host ke host lainnya.[3] Seluruh data itu harus melewati setiap layer-layer, agar sampai ke host tujuan. Misalnya saat anda mengirim email ke komputer lain dalam suatu jaringan yang sama. Proses yang paling pertama ada pada application layer, yaitu menyediakan program aplikasi email. Di sebuah presentation layer, email itu dikonversi menjadi sebuah format dalam jaringan. Lalu pada session layer, akan dibentuk lagi sesi perjalanan data itu dari mulai dibentuk sampai selesainya proses pengiriman tersebut. Di sebuah transport layer akan dipecah menjadi beberapa bagian kecil, lalu akan dikumpulkan lagi kepada transport layer penerima. Dalam network layer akan dibuatkan alamat, dan ditentukan juga jalan yang dilalui oleh data tersebut agar sampai ke tujuan. Dalam data link layer, data akan 
dibentuk menjadi sebuah frame dan alamat fisik dari perangkat pengirim dan juga penerima yang sudah ditetapkan. Pada layer terakhir yaitu physical layer, akan mengirimkan data itu melalui medium jaringan. Yang menuju ke lapisan transport si penerima. Setelah itu alur yang sama akan terjadi di komputer penerima, tetapi dimulai dari layer yang paling bawah. Sampai ke layer yang paling atas.

Dari hal-hal diatas, maka penguatan (hardening) pada suatu server sangatlah dipelurkan guna menghindari kerugian-kerugian yang tidak diinginkan oleh pihak pengelola dan client. Namun, kali ini metode hardening yang digunakan pada server linux hanya dioptimalkan pada layer pertama (physical) dan layer ketujuh (application). Dikarenakan kebutuhan pengamanan sistem di dalam layer 1 yang meliputi keamanan perangkat sampai dengan sistem operasi. Kemudian di dalam keamanan layer 7 menyangkut interkoneksi antar client ke server. Kalau hanya dilakukan hardening pada layer 7 saja, banyak client yang tidak termonitor dan dapat melakukan perubahanperubahan terhadap server serta dapat mengganggu kinerja server. Layer 1 sendiri berfokus untuk user management dan hardware management pada server. Penguatan sistem keamanan di layer 1 pun terpacu pada konfigurasi media transmisi yang juga merupakan tempat awal pengelolaan dan tempat awal dikirimkannya paket data menuju layer-layer selanjutnya.

\section{METODOLOGI PENELITIAN}

Perancangan yang akan dibuat bertujuan untuk membangun sebuah infrastruktur keamanan pada layer 1 dan layer 7 dalam sebuah server. Layer 1 adalah layer pyshycal yang tidak hanya meliputi kabel koneksi serta perangkatperangkat jaringan. Physical layer juga meliputi harddisk, BIOS serta linux kernel yang menjembatani antara komunikasi perangkat keras serta perangkat lunak. Interkoneksi antar perangkat yang terjadi didalam server juga dimaksud merupakan bagian dari layer physical. Kemudian layer application bertugas untuk mengatur bagaimana sebuah aplikasi mampu mengakses jaringan. Yang dalam hal ini dipertegas agar suatu aplikasi tidak menampilkan suatu anomaly (tersusupi maleware).

\subsection{Konsep Hardening di Layer 1 (Physical)}

Pengaturan fungsi perangkat keras di BIOS, berfungsi sebagai pengaturan perangkat-perangkat apa saja yang dapat dibaca dan digunakan langsung seperti USB drive, external keyboard, dll sebagai tingkat pencegahan awal untuk membatasi interaksi server ke media yang tidak diketahui atau dikenal.[2]

Pemfungsian server hanya akan terjadi via Secure Shell (SSH). Pengaturan ini juga meliputi pengaturan boot order disetiap perangkat apa saja yang memang digunakan sebagai bootable atau dapat di-booting secara default. Serta melakukan pemberian kata sandi di harddisk dan BIOS agar tidak mudah diakses oleh semua pengguna atau orang orang yang tidak bertanggungjawab.

Tabel 1. UID User

\begin{tabular}{cc}
\hline Jumlah User Identifier & Fungsi \\
\hline UID 0 (zero) & Digunakan untuk root \\
UIDs 1 -99 & Digunakan untuk akun yang telah ditentukan sebelumnya. \\
UID $100-999$ & Digunakan oleh sistem untuk administratif dan sistem \\
akun/grup \\
UID 1000 -10000 & Diisi oleh akun aplikasi-aplikasi \\
UID 10000+ & Digunakan untuk para pengguna (users) \\
\hline
\end{tabular}

Pengaturan dalam sisi sistem operasi berfungsi sebagai pembatas hak akses serta batasan-batasan apa saja yang dapat dilakukan admin dan client, seperti disable UID 0. Selain untuk user yang dapat sudo atau masuk sebagai root, hal tersebut juga untuk menghindari pengubahan yang dapat dilakukan oleh oknum (selain administrator) seperti yang tertera di tabel 1.[3]

Sebagai pencegahan dari kejahatan cyber juga diberikan konfigurasi keamanan seperti lock user. Ketika seorang user salah memasukan password, maka akan terdapat batas input kata sandi sebanyak tujuh kali. Kemudian password expiring time juga diberlakukan agar password selalu terbarui dan menyulitkan pihak lain untuk login. Adapun password di grub menu untuk mencegah seseorang selain administrator untuk dapat menggunakan fasilitas recovery yang disediakan linux. Hal tersebut guna menghindari oknum yang dengan sengaja ingin merubah konfigurasi dasar sistem pada server, serta disable ALT+CTRL+DEL di innitab yang terletak di grub konfigurasi agar setiap booting atau restart sistem operasi secara default langsung dapat membaca konfigurasi yang sudah dilakukan sebelumnya. [3]

\subsubsection{Alur Sistem Keamanan di Layer 1}

Flowchart pada gambar 1 merupakan gambaran tahapan admin sebelum masuk atau dapat mengakses server dari keadaan server yang digunakan dalm kondisi off. Admin harus memasukan kata sandi BIOS, HDD, kata sandi grub dan kata sandi pengguna untuk login ke dalam sistem operasi. Tetapi pada saat keadaan server sedang menyala admin hanya perlu memasukan kata sandi personal. Pada saat pengguna salah memasukan kata sandi 
JURNAL MEDIA INFORMATIKA BUDIDARMA

Volume 4, Nomor 3, Juli 2020, Page 591-603

ISSN 2614-5278 (media cetak), ISSN 2548-8368 (media online)

Available Online at https://ejurnal.stmik-budidarma.ac.id/index.php/mib DOI 10.30865/mib.v4i3.2157

dengan jumlah maksimal 7 kali, maka akun yang dimilikinya akan di kunci, dengan tujuan untuk menghindari hijack dengan metode bruteforce[6].

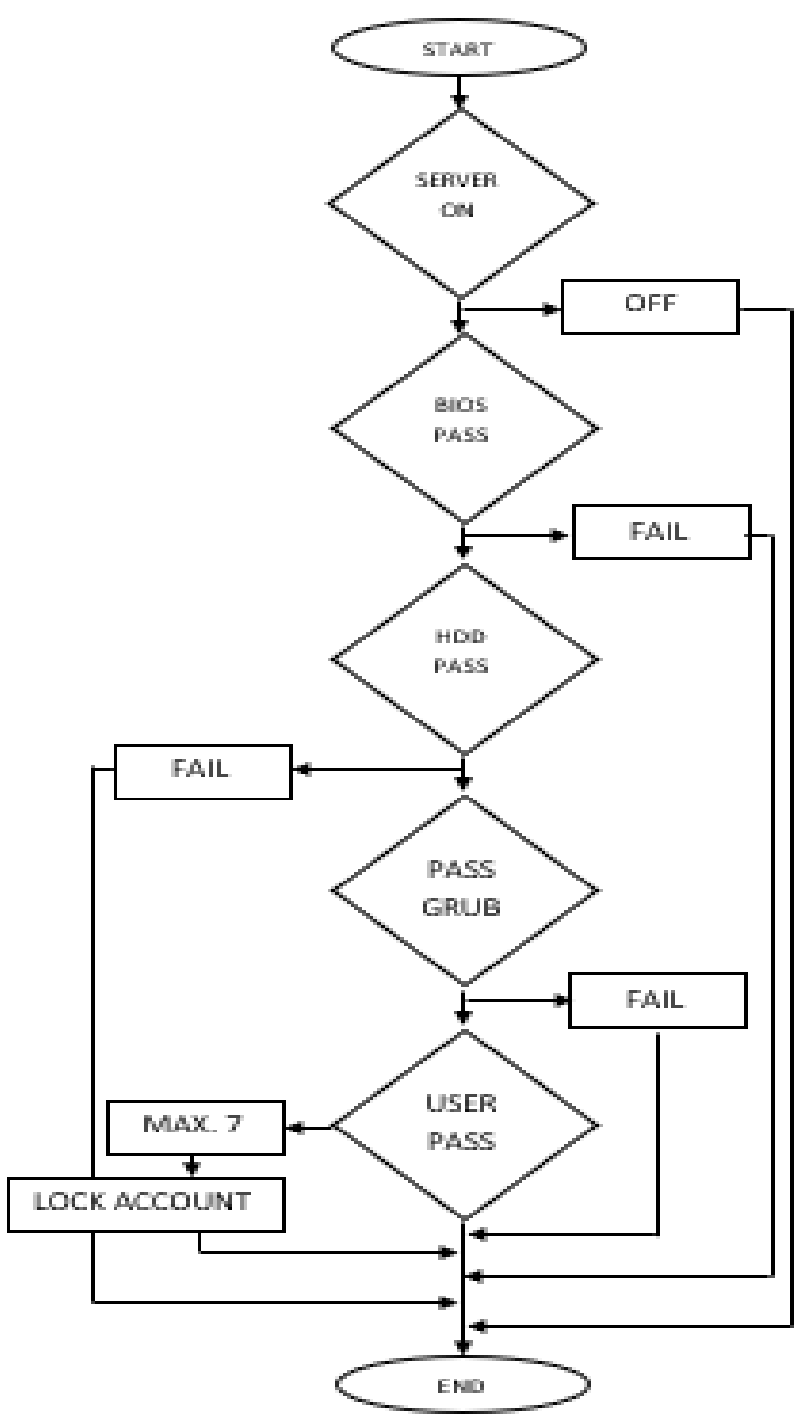

Gambar 1. Flowchart Sistem Keamanan di Physical Layer

Bruteforce adalah metode yang digunakan untuk mengetahui kata sandi dan nama pengguna dengan cara mencoba setiap kata sandi yang tepat secara acak, berdasarkan keyword yang di sediakan oleh attacker atau berdasarkan dictionary local yang sudah mereka persiapkan sebelumnya.[6]

\subsection{Konsep Hardening di Layer 7 (Application)}

Pada layer 7 sistem keamanan yang akan di rancang berkaitan dengan penggunaan aplikasi untuk melakukan monitoring terhadap akses data serta akses client ke server. Dalam hal ini Server menggunakan tools IDS dan IPS. IDS diperlukan sebagai langkah pencegahan awal serta monitoring terhadap perilaku client ke server. IPS sendiri digunakan sebagai langkah pencegahan awal terhadap segala sesuatu yang terjadi antar client dan server. IDS dan IPS yang digunakan adalah honeypot yang dilengkapi dengan berbagai macam fitur serta konfigurasi yang dapat di custom sesuai dengan kebutuhan untuk menjaga kinerja server agar tetap optimal.[5] Kemudian dilakukan juga langkah pencegahan berupa anti DOS supaya tidak memenuhi (over load) koneksi antar para user ke server dan agar tidak membebani penggunaan sumber daya server itu sendiri. Yang dimaksud sumber daya yaitu, processor, RAM serta data access.

\subsubsection{Alur Sistem Keamanan di Layer 7}

Flowchart pada gambar 2 di bawah, menggambarkan bagaimana cara kerja IDS/IPS snort, pada saat start. Diperlukan beberapa add on atau komponen tambahan yang digunakan sebagai web monitoring dan pembacaan log, snort yang difungsikan diatas juga menggunakan database Mysql sebagai alat untuk mempermudah pengumpulan dan analisa data dari server yang sedang beroperasi. 


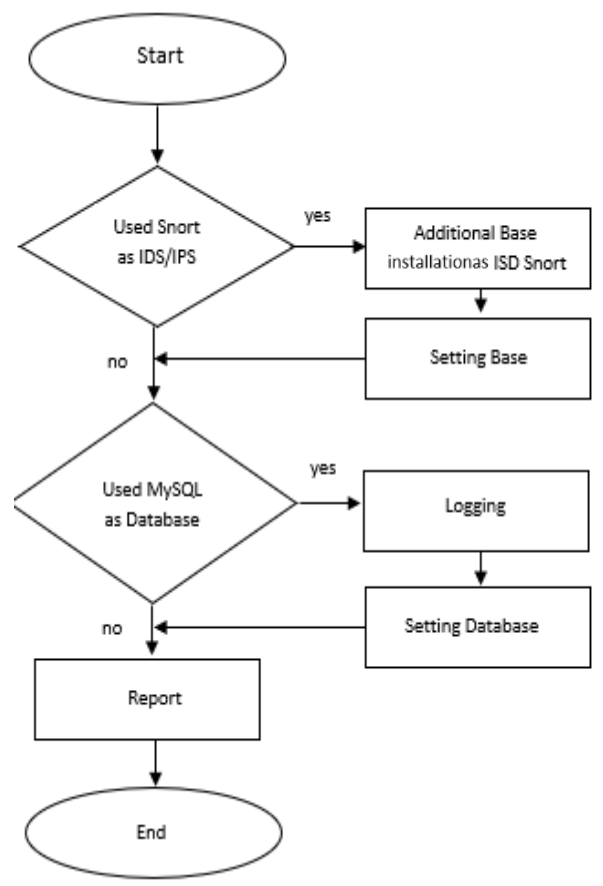

Gambar 2. Flowchart Alur Sistem Keamanan di Physical Layer

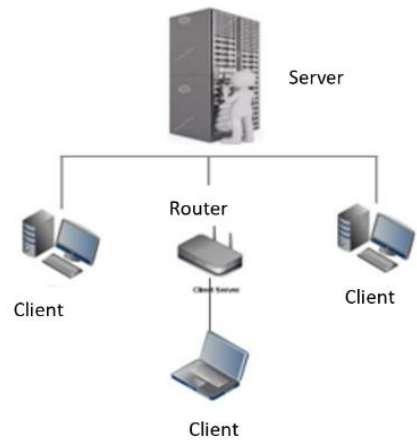

Gambar 3. Topologi Client Server

Pada penggambaran topologi diatas (Gambar 3) dapat terlihat saat pengguna mengakses server dari berbagai macam jenis interkoneksi, hanya administrator yang dapat melakukan akses fisik ke server dan melakukan interkoneksi langsung ke server, pada saat bersamaan client hanya dapat melakukan akses dari kejauhan dan menggunakan akun yang sudah dibatasi berdasarkan tingkatan serta keperluannya. Tingkat keamanan ini juga sangat membantu dalam meminimalisir terjadinya hal-hal yang tidak di inginkan seperti server down, service yang di berhentikan atau restart secara tidak sengaja. Terjadinya pembaruan pada beberapa aplikasi pun dapat menyebabkan aplikasi lain tidak dapat berjalan.

\section{HASIL DAN PEMBAHASAN}

Sistem operasi yang digunakan pada computer server adalah Linux Ubuntu versi 18.04 dengan versi kernel 5.3.0 berbasis 64 bit.

$\begin{array}{ll}\text { Operating system: } & \text { Linux } \\ \text { Operating system name: } & \text { Ubuntu Linux } \\ \text { Operating system version: } & 18.04 \\ \text { Kernel version: } & 5.3 .0 \\ \text { Hardware platform: } & \times 86 \_64\end{array}$

Gambar 4. Detail Computer Server Profile

Selanjutnya, dilakukan tahapan konfigurasi yang berkaitan dengan hardening pada layer 1 dan layer 7. Dalam hal ini konfigurasi dilakukan secara manual dan memperhatikan secara selektif terkait apa saja yang diperlukan untuk keamanan server. 
JURNAL MEDIA INFORMATIKA BUDIDARMA

Volume 4, Nomor 3, Juli 2020, Page 591-603

ISSN 2614-5278 (media cetak), ISSN 2548-8368 (media online)

Available Online at https://ejurnal.stmik-budidarma.ac.id/index.php/mib

DOI 10.30865/mib.v4i3.2157

\subsection{Tahapan dan Perancangan Konfigurasi Sistem Keamanan Server}

a. Konfigurasi Kernel Terhadap Aplikasi

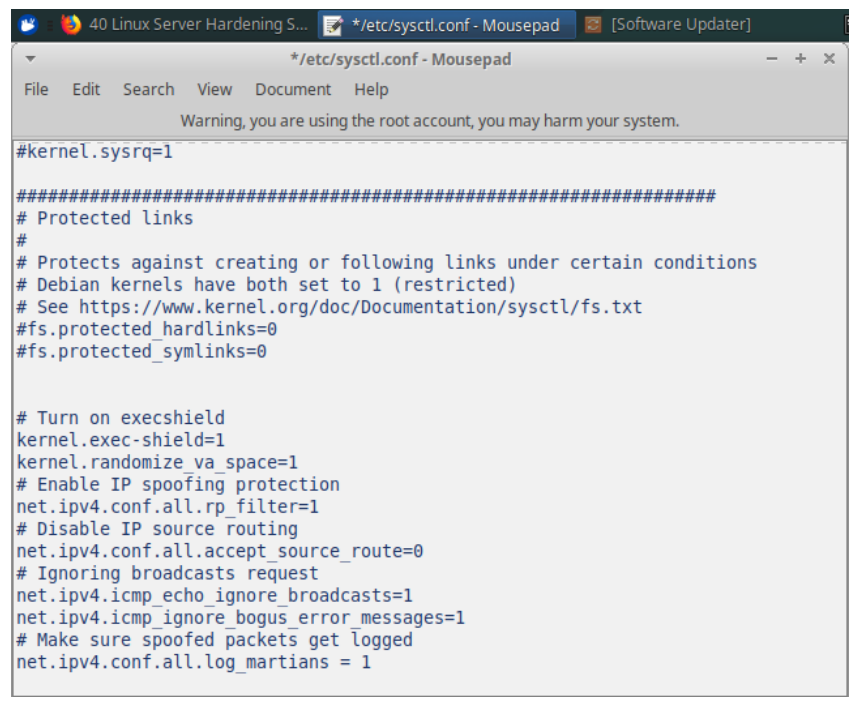

Gambar 5. Konfigurasi Kernel Terhadap Aplikasi

Konfigurasi ini digunakan untuk mengaktifkan modulasi kernel dan berkaitan dengan keamanan aplikasi (layer 7) seperti:

1. IP Spoofing yang merupakan program pembuatan paket Protokol Internet dengan alamat IP palsu dan bertujuan untuk menyamar sebagai sistem komputer lain dalam suatu jaringan yang sama darimana asal mereka mengirim dan menerima data secara online. Tujuan IP Spoofing ini agar mereka tidak bisa dilacak saat melakukan tindak kejahatan di dunia maya. Contoh mudahnya adalah tindakan DdoS.

2. IP source routing adalah tekbik untuk melihat tujuan pengirman data

3. Ignoring broadcast request adalah metode yang di gunakan untuk menolak ping atau ICMP packet yang dikirim ke dalam server

Hal ini dilakukan pada tahapan pertama untuk melakukan kompilasi terhadap modul-modul penunjang konfigurasi hardening lainnya ditahapan selanjutnya.

\section{b. Konfigurasi Aplikasi Needrestart}

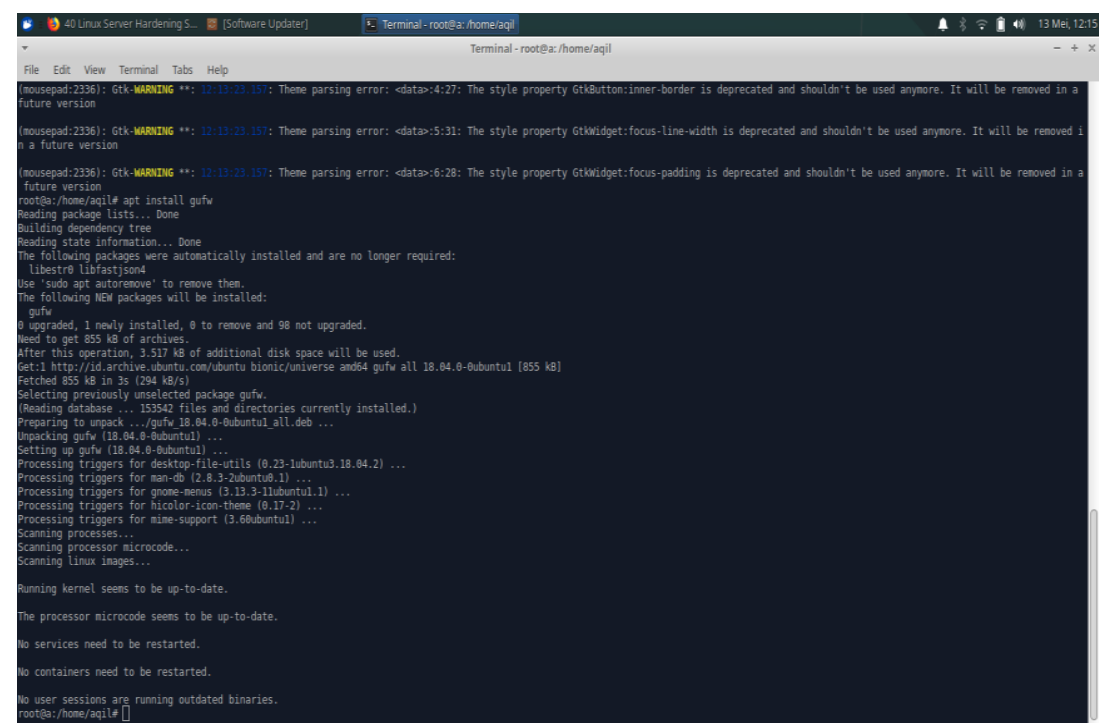

Gambar 6. Instalasi Aplikasi Needrestart

Setelah tahapan konfigurasi pada system kernel, selanjutnya dilakukan instalasi aplikasi needrestart yang dimana aplikasi tersebut dibutuhkan untuk mengetahui notifikasi berupa paket aplikasi atau kernel yang belum ter-update dan serta docker service yang perlu di restart, log dari aplikasi ini juga sangat memudahkan dalam pembacaan serta pengecekan apakah server masih optimal dengan konfigurasi yang ada nantinya. 
JURNAL MEDIA INFORMATIKA BUDIDARMA

Volume 4, Nomor 3, Juli 2020, Page 591-603

ISSN 2614-5278 (media cetak), ISSN 2548-8368 (media online)

Available Online at https://ejurnal.stmik-budidarma.ac.id/index.php/mib

DOI $10.30865 /$ mib.v4i3.2157

\section{c. Konfigurasi /etc/shadow}

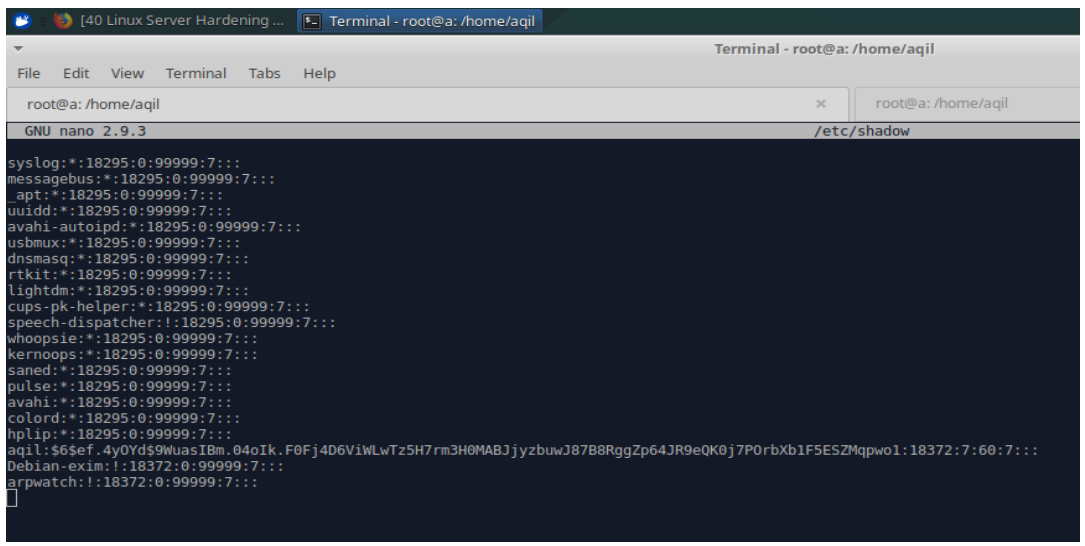

Gambar 7. Konfigurasi /etc/shadow

Pada konfigurasi pada /etc/shadow dilakukan dengan tujuan untuk memberikan jangka waktu terhadap password yang di gunakan oleh client, agar password yang digunakan selalu ter-update. Password yang lama pun akan kadaluarsa.

\section{d. Konfigurasi Kernel Terhadap Sistem Operasi}

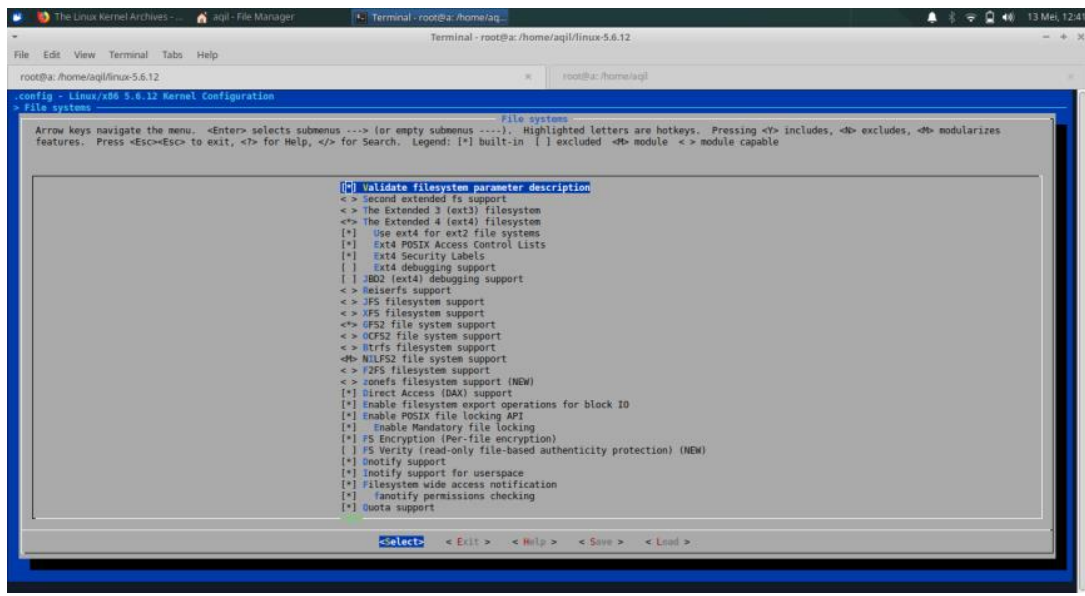

Gambar 8. Konfigurasi Kernal Untuk Sistem Operasi

Dalam tahapan ini dilakukan konfigurasi lebih lanjut terhadap kernel secara manual dengan tujuan untuk memaksimalkan kinerja sistem operasi yang di gunakan serta menonaktifkan fitur fitur apa asaja yang tidak di perlukan untuk meringankan kinerja server seperti di gambar 8. Gambar tersebut menunjukan konfigurasi kernel untuk membaca format hardisk. Hanya ext4 yang di perbolehkan (enable) Hal tersebut berkaitan dengan penguatan pada layer 1.

\section{e. Konfigurasi Sistem Keamanan Kernel}

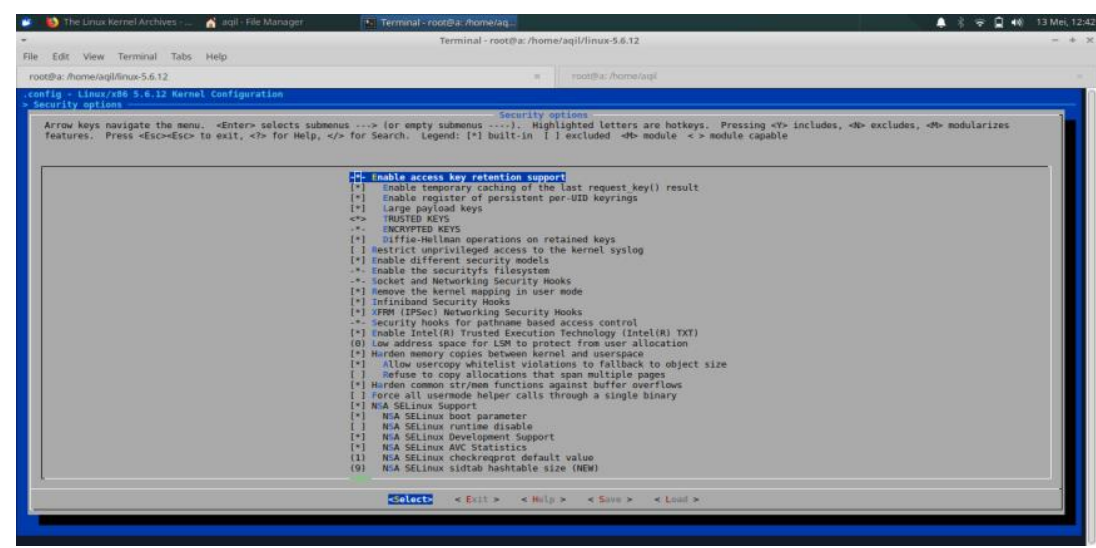

Gambar 9. Konfigurasi Sistem Keamanan Kernel 
JURNAL MEDIA INFORMATIKA BUDIDARMA

Volume 4, Nomor 3, Juli 2020, Page 591-603

ISSN 2614-5278 (media cetak), ISSN 2548-8368 (media online)

Available Online at https://ejurnal.stmik-budidarma.ac.id/index.php/mib

DOI 10.30865/mib.v4i3.2157

Dalam tahap dan konfigurasi ini dilakukan pemilihan security untuk dapat dioptimalkan sesuai dengan kebutuhan server seperti pemanfataan dan pemilihan aplikasi SELinux. SELinux adalah aplikasi yang digunakan untuk memfilter user dengan process. Aplikasi mendasar yang dipakai dalam penerapan SELinux adalah layanan FTP dan HTTP. Kalau dalam proses tradisional user langsung dikontrol oleh daemon dari FTP dan HTTP. Maka dengan penerapan SELinux ini, user dipetakan ke SELinux kemudian SELinux akan menentukan boleh dan tidaknya user untuk mengakses FTP dan HTTP. Jadi SELinux ini memberi keamanan tambahan antara user dengan proses. Di sinilah tingkat keamanan pertama kali dicek oleh system. Hal ini berkaitan dengan hardening dalam layer 1.

\section{f. Konfigurasi Driver}

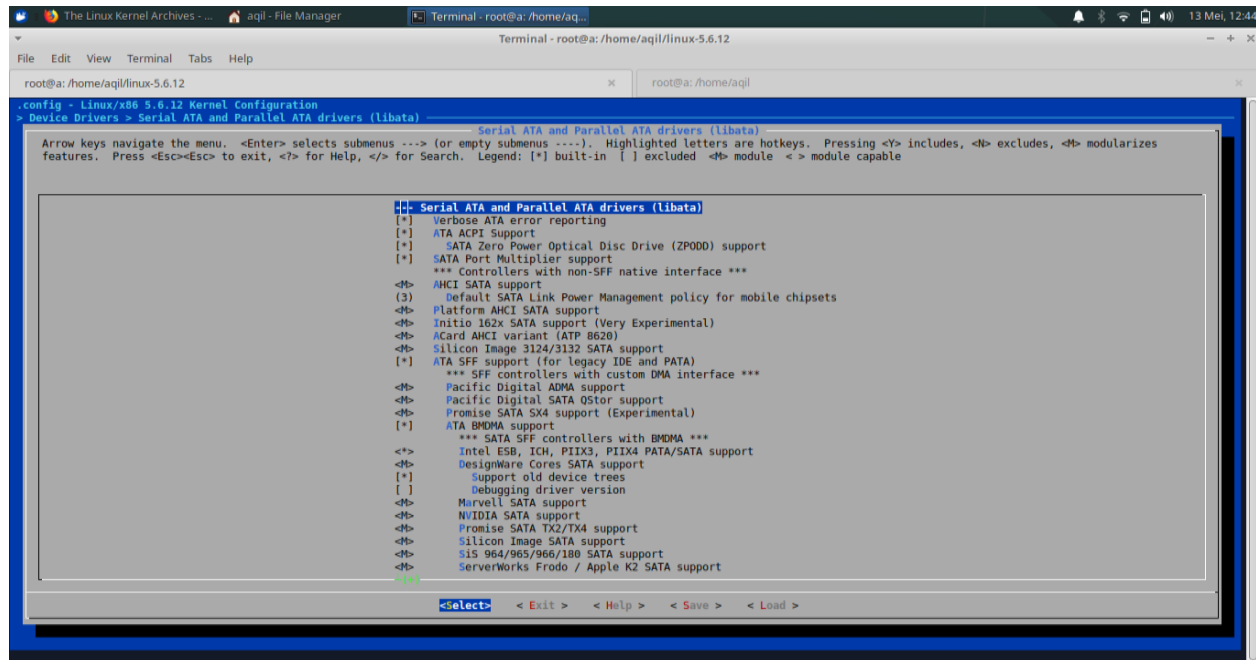

Gambar 10. Konfigurasi Driver

Pada bagian ini dilakukan optimalisasi pada driver. Hanya driver yang berkaitan dengan perangkat (server) saja yang digunakan dan diinstal. Optimalisasi ini bertujuan untuk meringankan serta memimalisir interkoneksi perangkat dari BIOS dan kernel agar tidak membebani kinerja server. Hal tersebut juga untuk mengamankan server dari client baru, yang dimana client tersebut harus melakukan resgistrasi/didaftarkan terlebih dahulu ke dalam sistem agar dapat melakukan interkoneksi dalam jaringan. Adapun pemilihan isolasi yang bertujuan agar perangkat-perangkat yang tidak di kenal tidak membebani dan mengganggu kinerja server. Sebagaimana dimaksud tingkat keamanan kali ini untuk layer 1 dan 7.

\section{g. Konfigurasi Jaringan}

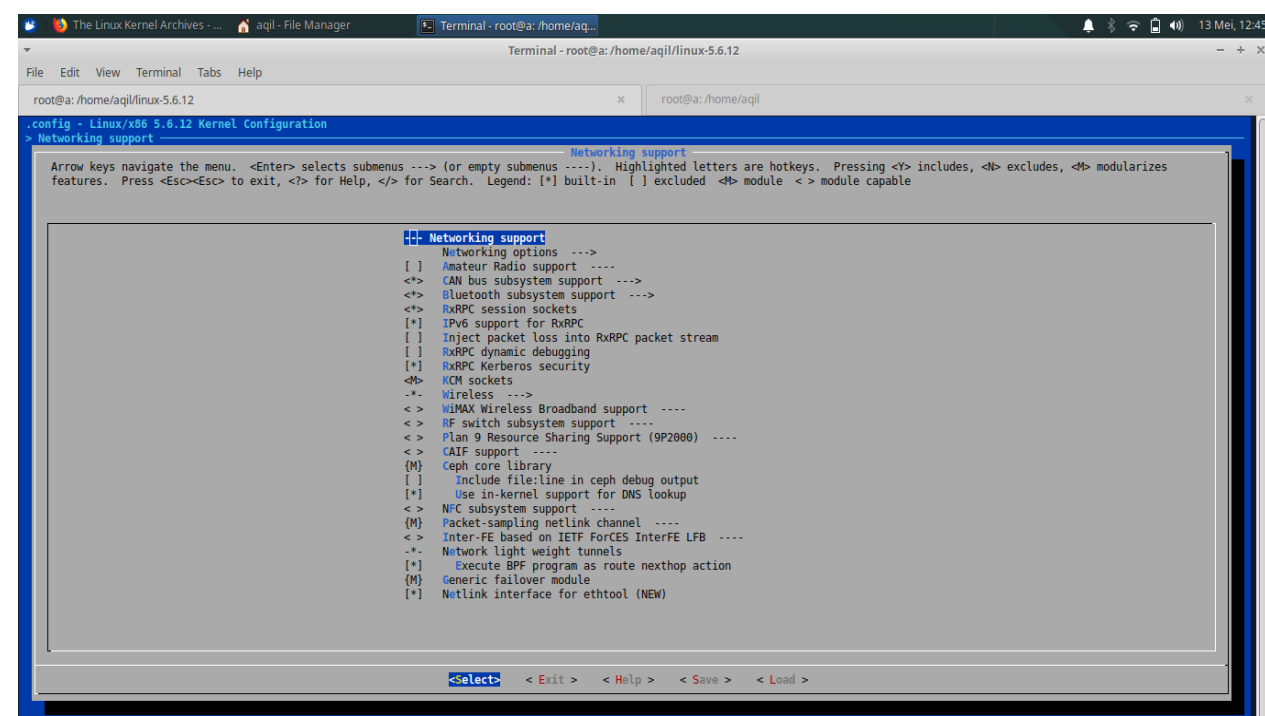

Gambar 11. Konfigurasi Jaringan

Kali ini dilakukan optimasi networking, perangkat serta modulasi network apa saja yang digunakan yang sesuai dengan keperluan yang digunakan seperti disable ipv6, disable nfc, disable wimax, disable wireless, disable bluetooth. Penyesuaian serta konfigurasi di atas juga sebagai langkah pencegahan agar tidak terjadi attacking dengan meenyerang perangkat yang aktif tetapi tidak di gunakan, serta sebagai pembatasan agar perangkatperangkat baru yang belum terdaftarkan tidak dapat di gunakan untuk melakukan interkonteksi. Langkah ini untuk penguatasn pada sistem keamanan di application layer. 


\section{h. Konfigurasi Security Shell}
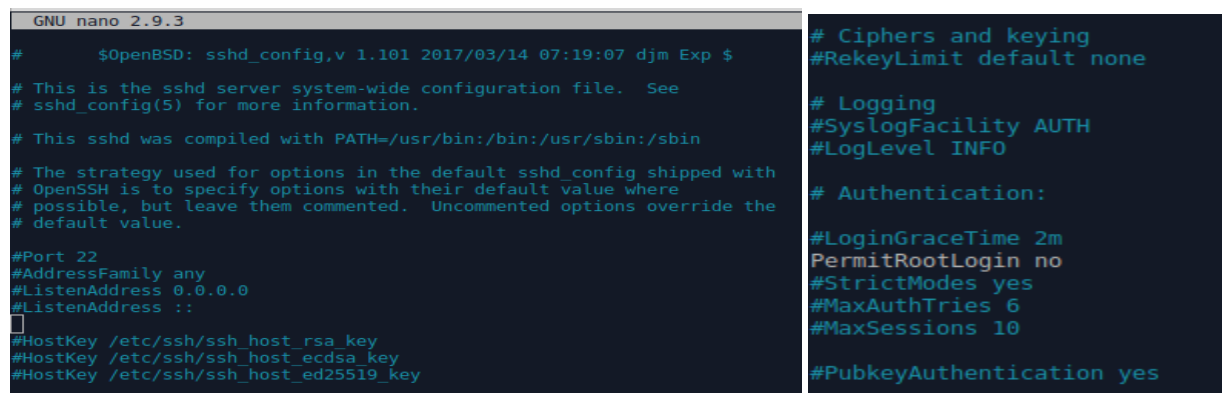

Gambar 12 \& 13. Konfigurasi Security Shell (SSH)

Konfigurasi ini dilakukan pembatasan pada SSH server yaitu, user selain admin tidak dapat login sebagai root, user tidak dapat login jika memasukan yang salah dan dibatasi sebanyak 7 kali,dan tidak dapat login dengan user serta ip address yang tidak terdaftar dalam jaringan. Hal ini pun semakin optimal, karena dalam tahap konfigurasi driver dan konfigurasi jaringan sudah dilakukan dan hal ini dapat dikatakan sebagai tingkat keamanan berlapis pada layer 7. Dengan optimasi yang sudah dilakukan sampai tahap ini server jadi jauh lebih mudah di monitoring. Admin pun dapat mematikan layanan atau aplikasi yang dapat mengganggu kinerja server.

\section{i. Konfigurasi Firewall}

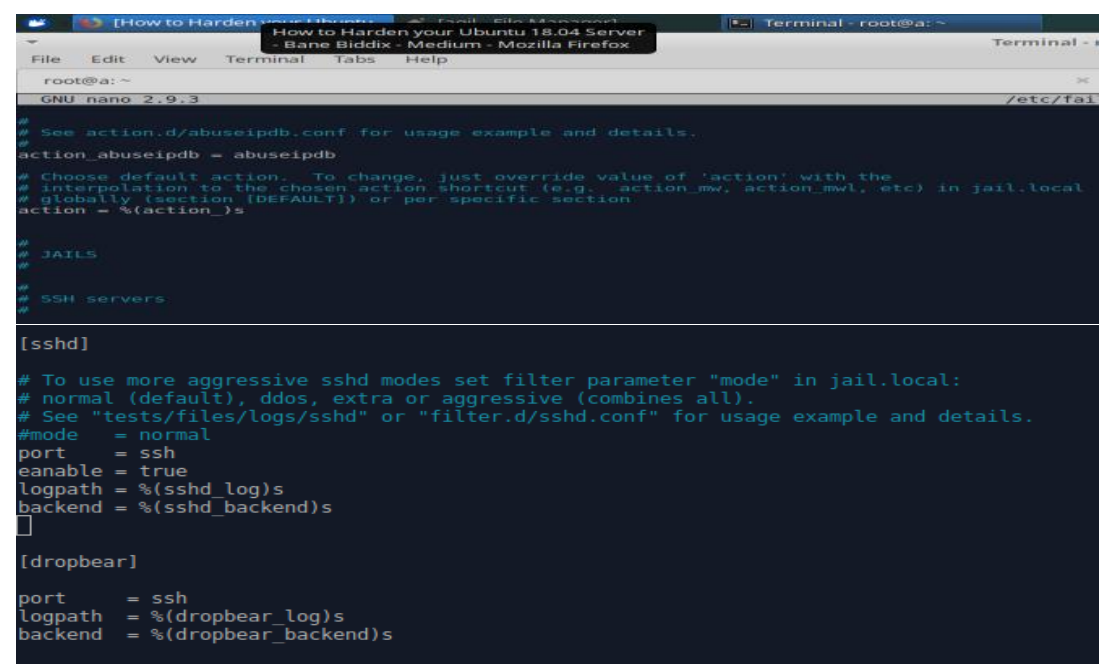

Gambar 14. Konfigurasi Firewall

Pada konfigurasi bagian ini mengacu pada sistem keamanan di layer 7. Dalam tahap ini dilakukan pengamanan pada firewall. Konfigurasi ini bertujuan untuk melakukan pencegahan lebih lanjut terhadap external user (attacker) yang mencoba login dengan berulang kali atau bruteforce dalam interval yang singkat. IP address attacker akan di blacklist dan di drop setiap kali melakukan request yang di jalankan terhadap serve. Hal ini bertujuan untuk mencegah penurunan performa karena pembanjiran (load data) request ke dalam server.

\section{j. Konfigurasi User Login}

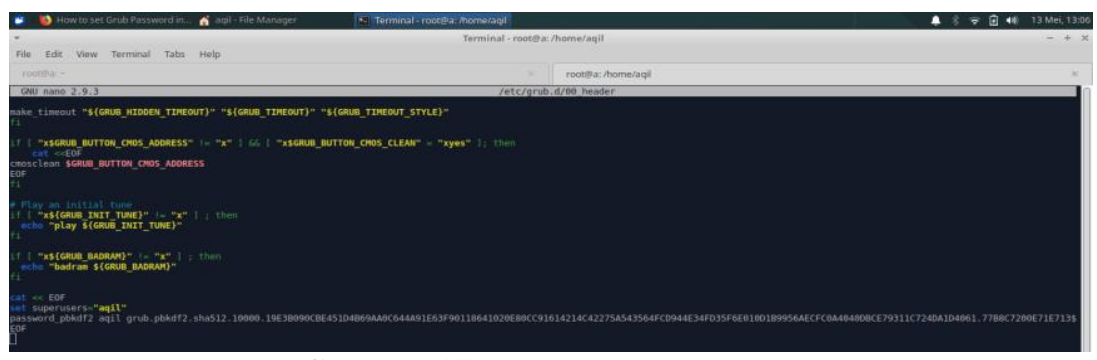

Gambar 15. Konfigurasi User Login

Konfigurasi ini bertujuan untuk mendaftarkan username beserta password sebelum dapat masuk kedalam grub menu, agar setiap kali server melakukan restart, user tidak dapat langsung masuk ke menu recovery. Hal tersebut dilakukan untuk meminimalisir user yang tidak terdaftar atau tidak bertanggungjawab dan melakukan registrasi kedalam list yang tersedia. Username dan password yang digunakan pun berbeda untuk login ke dalam server. Hal 
ISSN 2614-5278 (media cetak), ISSN 2548-8368 (media online)

Available Online at https://ejurnal.stmik-budidarma.ac.id/index.php/mib DOI 10.30865/mib.v4i3.2157

ini pun dapat dikatakan sebagai tingkat keamanan berlapis untuk layer 7. Setelah dilakukan berbagai konfigurasi diatas yang bertujuan untuk menunjang sistem keamanan server, maka setelah itu dilakukan pengecekan dengan aplikasi audit lynis. Lynis adalah aplikasi audit keamanan open-source berbasis host yang dapat mengevaluasi profil keamanan dan postur Linux.

\subsection{Tahap Pengecekan}

Pada saat sistem audit berjalan, sistem menampilkan pengecekan terhadap software dan hardware yang menunjang penguatan (hardening) pada server.

\section{a. Checking System Binaries}

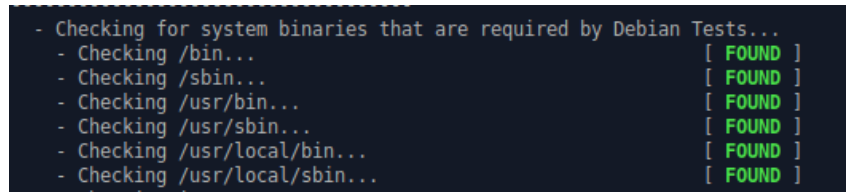

Gambar 16. Checking System Binaries

Pada gambar 5 menunjukan bahwa program telah melakukan pengecekan di sistem binari. Sistem binari sendiri merupakan system yang berkaitan dengan profile dan log user. Gambar 2 menunjukan bahwa file-file profile user menunjang computer untuk dijadikan server.

\section{b. Checking File System}

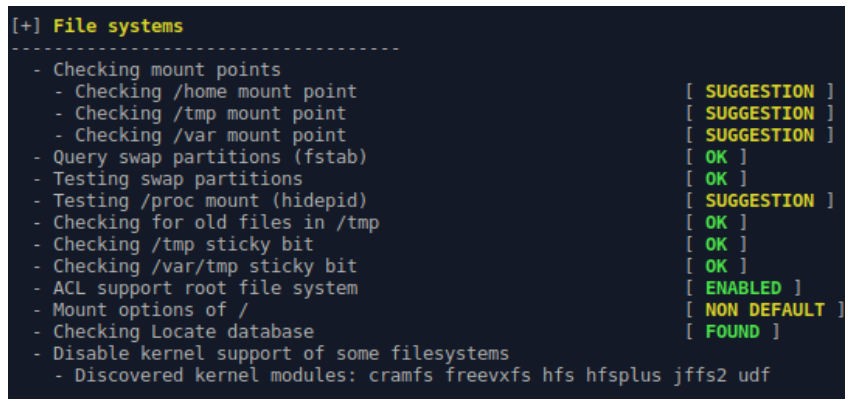

Gambar 17. Checking File System

Pada saat audit atau dilakukan pengecekan pada file system, terdapat direktori-direktori yang menunjukan bahwa file-file yang terdapat dalam sistem dalam kondisi yang baik. Berikut penjelasan terkait hasil pengecekan :

1. Chceking mount point adalah proses pengecekan mounting file system ke dalam volume disk yang berbeda, yang nantinya akan memudahkan dalam proses disaster recovery apabila terjadi suatu insident.

2. Query swap partition, pengecekan konfigurasi swap di dalam sIstem, apakah partisi swap dapat dipisah menggunakan high speed storage seperti SSD untuk meningkatkan kinerja server.

3. Testing swap partition, merupakan pengetesan konfigurasi pada VM.swappiness, sebagai fungsi berapa persen RAM yang digunakan dan dapat dialihkan untuk pembebanan cache ke dalam swap.

4. Checking all /tmp or the temporary files, fungsi tersebut biasanya dilakukan dengan satu langkah konfigurasi saja, dan setelah itu dapat dihapus. Dan disini hal tersebut dilakukan secara otomatis oleh sistem.

5. ACL support root file system, menunjukan konfigurasi bahwa tidak semua pengguna yang terdaftar dapat menggunakan sudo atau sebagai root user. Dalam hal ini tidak semua pengguna (client user) yang sudah terdaftar pada server dapat melakukan konfigurasi pada server, hanya administrator saja yang dapat melakukannya.

6. Mount point of /, digunakan untuk defaulting konfiurasi pada sistem operasi.

7. Disable kernel support of some file system, yang berarti tidak semua file sistem dapat melihat dan melakukan editing pada system tanpa permission dari admin

c. Checking in Kernel

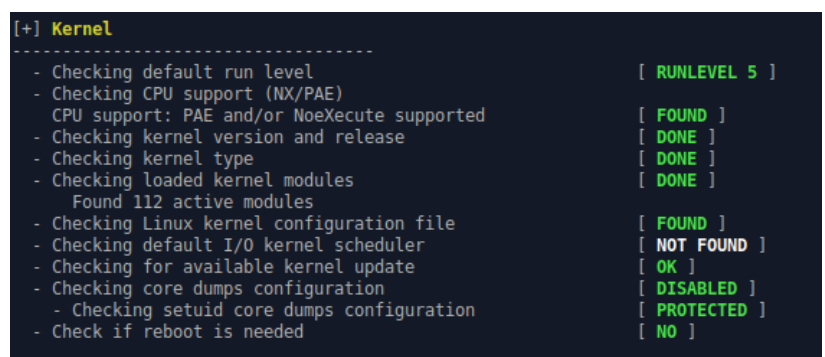

Gambar 18. Chekhing Kernel 
1. Pada sistem kernel telah dilakukan pengecekan. Kernel sendiri adalah sebuah program yang merupakan inti pokok dari sebuah sistem operasi. Kernel memiliki kontrol yang komplit atas segala sesuatu yang berlangsung dalam sistem. Kernel menyediakan layanan dasar untuk bagian-bagian lain dari sistem operasi, khususnya manajemen memori, proses, file dan inputt/output. Kernel merupakan suatu program yang menjembatani software dengan hardware melalui system call.

2. Adapun pengecekan yang dilakukan pada physical address extension (PAE) untuk arsitektur sistem operasi x86(32 bit) dan No.-execute (NX) untuk arsitektur sistem operasi 64 bit. PAE/NX merupakan fitur untuk manajemen memori.

3. Kemudian terdapat pengecekan pada konfigurasi core dums, yaitu file yang beisi alamat memori untuk mengatasi drop out proccess.

\section{d. Checking Memory and Process}

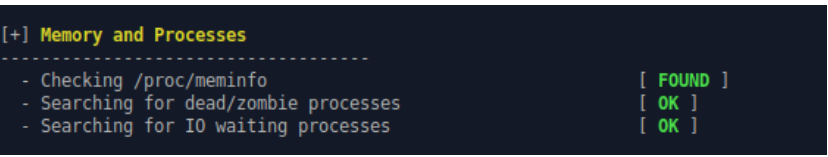

Gambar 19. Checking Memory and Process

1. Lalu adapun pengecekan (/proc/meminfo) yang berfungsi untuk mengetahui jumlah memori bebas dan bekas (baik fisik dan swap) pada sistem serta memori bersama dan buffer yang digunakan oleh kernel.

2. Dead/zombie proccess adalah proses yang telah selesai namun masih dalam tabel proses karena kurangnya korespondensi dan biasanya hal tersebut selalu terpantau melalui fungsiwait I/O. Pada sistem diatas, hal-hal tersebut dinyatakan dalam kondisi prima/baik.

\section{e. Checking User, Groups, and Administrator}

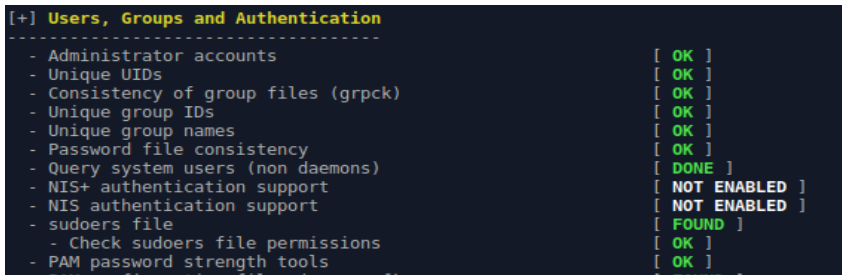

Gambar 20. Checking Users, Group and Administrator

Konfigurasi user dan group password diatur oleh program Password Autentichation Modules (PAM) dengan berbagai karakter yang unik atau kombinasi alfabet, angka, maupun simbol. Kemudian sudoers file sendiri diatur hanya untuk beberapa pengguna saja, dan tidak semua user dapat melakukan command pada server, hanya administrator. User Identifier dan Group User Identifier sendiri pada server, tidak dapat diubah secara menual. Hal tersebut hanya dapat diubah melalui file konfigurasi di direktori etc, dan hanya dapat dilakukan oleh administrator

\section{f. Chehking Fungtion of USB Device and Storage}

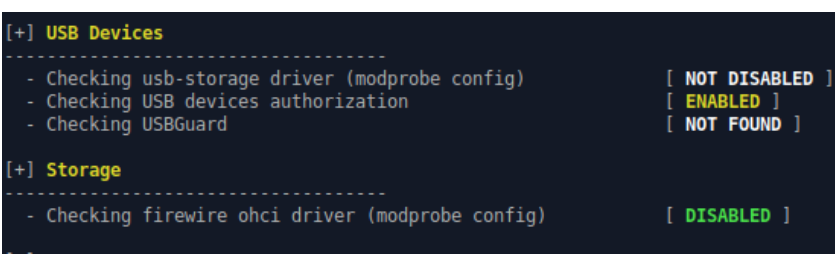

Gambar 21. Checking USB Devices and Storage

Pada bagian ini telah dilakukan penonaktifan pada modprobe config. Karena tidak semua modul pada kernel dapat berjalan secara automatic ataupun manual. Karena untuk menjalankan suatu modul diperlukan kompilasi kernel baru

\section{g. Checking Name Services}

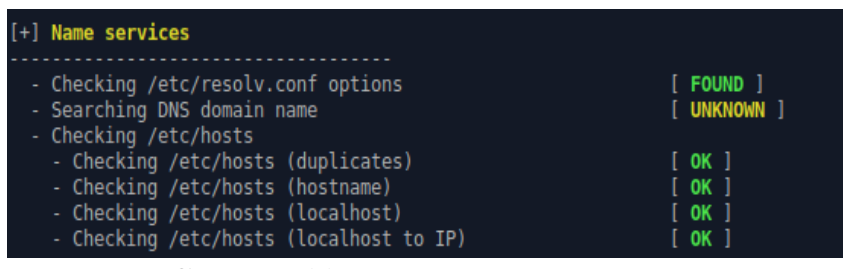

Gambar 22. Checking Name Servives 
JURNAL MEDIA INFORMATIKA BUDIDARMA

Volume 4, Nomor 3, Juli 2020, Page 591-603

ISSN 2614-5278 (media cetak), ISSN 2548-8368 (media online)

Available Online at https://ejurnal.stmik-budidarma.ac.id/index.php/mib

DOI 10.30865/mib.v4i3.2157

Konfigurasi name services diatur secara manual dan tidak terdapat DHCP untuk server, hanya computer client saja yang mendapatkan alamat dari DHCP router.

h. Checking Networking

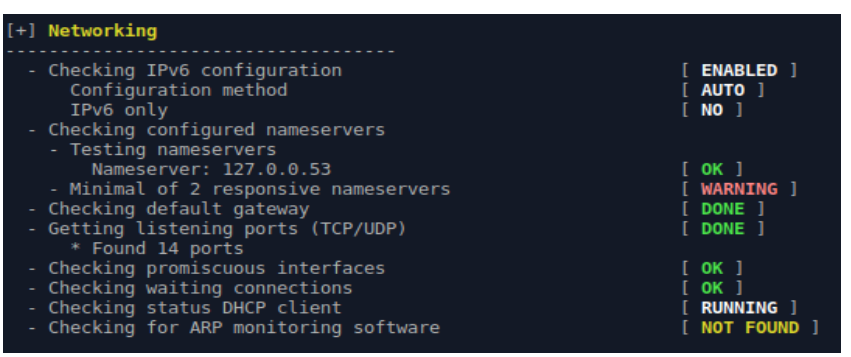

Gambar 23. Checking Networking

Pada bagian networking, telah dilakukan penonaktifan pada IPv6. Hal tersebut dilakukan untuk menghindari kerentanan. Karena melalui konfigurasi IPv6, user dapat dengan bebas mengatur dan mengubah IP statis dan VLAN. Untuk membuat kinerja server ringan dan dapat dipantau, kita hanya mengaktifkan IPv4. Dalam hal ini ARP yang sudah terpasang dalam device firewall pun tidak perlu membuat server bekerja dengan keras untuk melakukan dua hal secara bersamaan.

\section{i. Checking Printer and Spools}

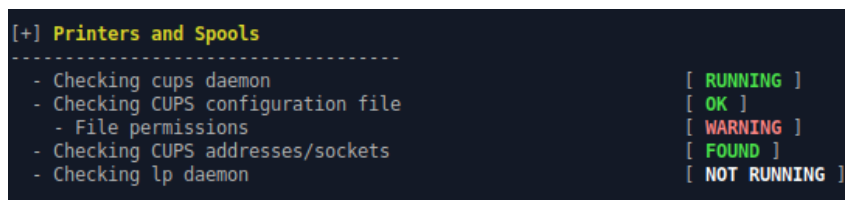

Gambar 24. Checking Printer and Spools

Pada bagian ini juga dilakukan penonaktifan guna menghindari kerentanan melalui socket dan port pada computer server.

\section{j. Checking Software for mail messaging}

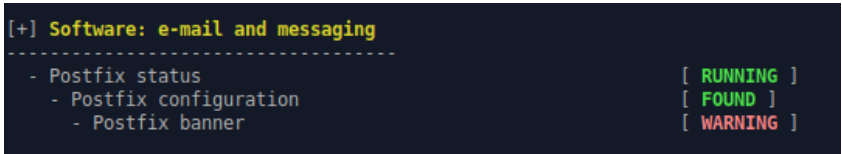

Gambar 25. Checking Software for mail messaging

Tidak dilakukan pemasangan, sebab guna meminilisir serangan maleware yang dapat dilakukan dengan pengiriman $e$-mail dan pesan.

k. Checking Software Firewall

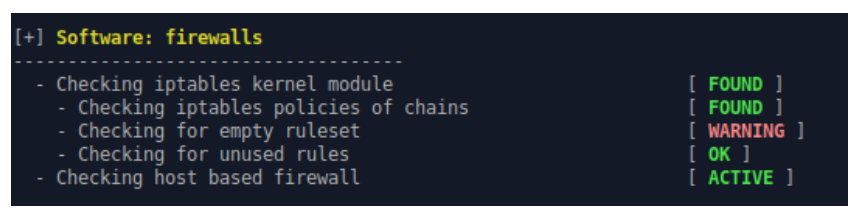

Gambar 26. Checking Software Firewall

Pemasangan firewall sudah dilakukan secara manual melalui command line agar dapat dengan mudah mengatur interconnection dan penerimaan atau penolakan dari alamat yang tidak diketahui.

\section{Ports and Packages}

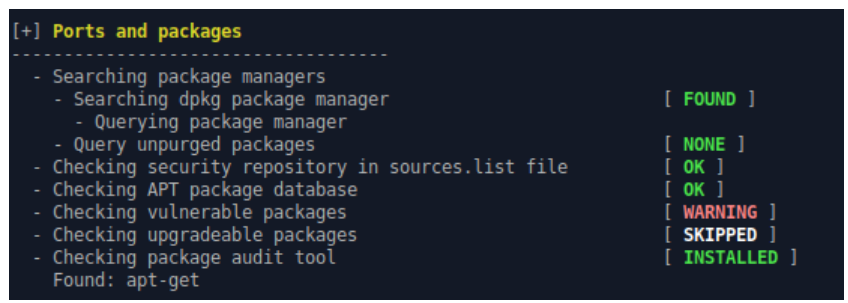

Gambar 27. Checking Ports and Packages 
JURNAL MEDIA INFORMATIKA BUDIDARMA

Volume 4, Nomor 3, Juli 2020, Page 591-603

ISSN 2614-5278 (media cetak), ISSN 2548-8368 (media online)

Available Online at https://ejurnal.stmik-budidarma.ac.id/index.php/mib

DOI 10.30865/mib.v4i3.2157

Pada bagian ini packeages terindikasi dalam kondisi warning karena aplikasi listbugs tidak dilakukan update sejak tahun 2017 pada operating system yang digunakan. Terkait hal tersebut maka dilakukan improvisasi secara manual pada packeages melalu versi pada -apt yang sudah dikemas sesuai kebutuhan. Improvisasi ini lebih rumit, tetapi hal tersebut dilakukan untuk keamanan yang lebih baik, dibandingkan melakukan instalasi dan menjalankan konfigurasi paket terbaru. Karena tidak semua update yang ditawarkan oleh pengembang dari sistem operasi itu baik

\section{m. Checking Crontab/Cronjob}

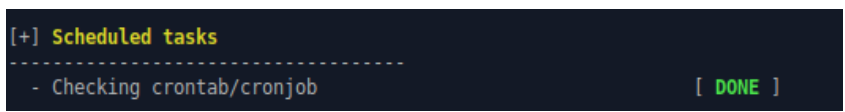

Gambar 28. Checking Schedule Task

Digunakan untuk otomatisasi perintah berulang, seperti membersihkan cache RAM, menghapus temporary files dan $\log$.

\section{n. Checking Security Fremeworks}

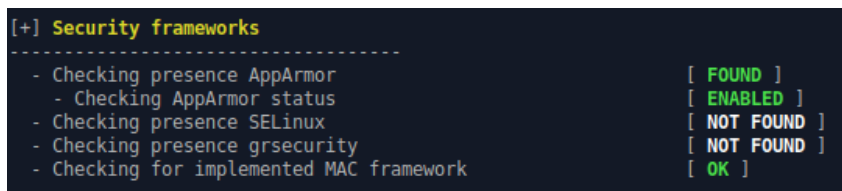

Gambar 29. Checking Security Frameworks

Pada gambar 10 menunjukan, aplikasi keamanan AppArmor telah diinstal secara manual pada sistem kernel. Namun penginstalan selinux dan grsecurity tidak dilakukan, sebab disini hanya menggunakan aplikasi resmi yang disedikan oleh kernel.

\section{o. Checking Time Synchronization}

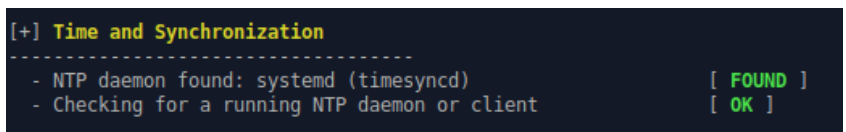

Gambar 30. Checking Time Synchronization

Menunjukan bahwa waktu didalam system sudah tersinkronasi dengan daerah/wilayah secara online.

p. Checking Crypography

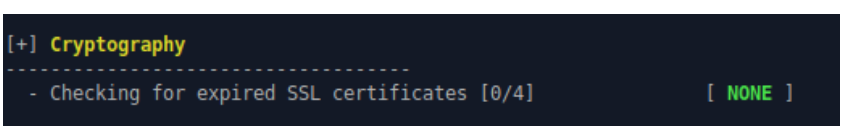

Gambar 31. Checking Crypography

Pengecekan pada sertifikat SSL menunjukan 'none', sebab SSL certificates akan update dalam satu minggu sekali dan dilakukan secara manual yang sekaligus terhubung di cronjob command.

\section{q. Checking Secure Shell Support}

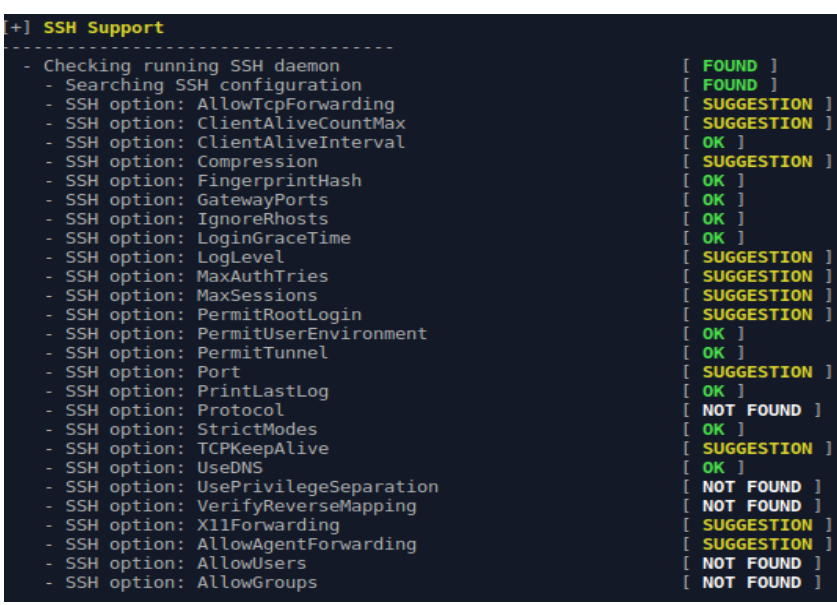

Gambar 32. Checking Secure Shell Support

Maraghi Agil Prabowo, Copyright (C2020, MIB, Page 602 
Pada bagian ini konfigurasi dilakukan secara default sesuai dengan sistem operasi yang disediakan. Namun root login dinonaktifkan dan hanya beberapa user saja yang dapat melakukan akses pada Secure Shell (SSH). SSH adalah sistem yang memungkinkan para pengguna untuk melakukan kontrol (remote) pada server.

Terdapat 2 tahapan dalam melakukan metode hardening ini, pertama melakukan konfigurasi berdasarkan kebutuhan sistem keamanan untuk layer 1 dan layer 7, kedua melakukan pengecekan terkait hal-hal yang sudah dikonfigurasi apakah sudah sesuai dengan hasil (report) dari pengecekan. Dan hasil yang ditampilkan pun sudah sesuai dengan apa yang sudah dikonfigurasi. Kemudian dari apa yang sudah dikerjakan dapat diketahui, bahwa sistem keamanan yang dikonfigurasi dan dipasang pada layer 1 dan 7 terbilang kompleks dan merupakan sistem keamanan berlapis, sebab sistem keamanan ini mengacu untuk menghindari oknum (attacker) yang menyerang sistem keamanan server melalui tindakan bruteforce dan oknum jahil yang terdapat di area internal.

\section{KESIMPULAN}

Pada dasarnya sistem keamanan pada suatu jaringan sangatlah penting dan tidak dapat dipungkiri kejahatan di dunia cyber pun semakin beragam. Berbagai perangkat keamanan sudah tersedia di jaman sekarang ini, sebab teknologi semakin berkembang dari masa ke masa, begitu pun software-software pendukung sistem keamanan. Berhubung dengan hal tersebut sistem keamanan jaringan sendiri diatur melalui sebuah computer server. Mulai dari pembatasan user, layanan yang disediakan untuk client, sampai access permission. Dari hasil dan pembahasan diatas terkait peracangan keamanan pada computer server berbasis linux telah dilakukan konfigurasi dan audit. Konfigurasi yang dilakukan pun secara manual dan dilakukan dengan selektif terkait kebutuhan untuk menunjang penguatan (hardening) pada sistem keamanan server. Kemudian ada pun pengecekan yang dilakukan menggunakan program audit lynis pada computer server. Hasil dari report yang ditampilkan pun sudah sesuai dengan apa yang sudah dikonfigurasi. Pada dasarnya apa yang dilakukan terkait hardening pada layer 1 dan layer 7 tidak dapat maksimal apabila pada layer 2 sampai dengan 6 tidak dilakukan pengamanan kendati sama halnya dengan layer 1 dan layer 7. Namun dalam hal ini layer 1 dan layer 7 hanya dilakukan opitimalisasi untuk tingkat keamanan yang lebih atau dapat dikatakan sebagai sistem keamanan berlapis. Apa yang dilakukan dalam metode hardening ini masih terdapat kekuarangan terkait sistem keamanannya, sebab hanya pada layer 1 dan 7 saja yang menjadi center of security method. Namun apa yang sudah dilakukan dalam pengerjaan dan prakteknya hanya merupakan bagian kecil dari banyaknya metode terkait pengamanan sistem jaringan pada sebuah server.

\section{REFERENCES}

[1] Sirait, F., Putra K. "Implementasi Metode Vulnerability Dan Hardening Pada Sistem Keamanan Jaringan". Jurnal Teknologi Elektro, Universitas Mercu Buana, Vol. 9 No. 1 Januari 2018.

[2] Sahari, S. (2017). Implementasi Sistem Keamanan Web Server Berbasis Distro Linux Debian \& Mikrotik Pada CV. Karya Baru Perabot. Pendidikan Teknologi Informasi UPI-YPTK, 3(1).

[3] Prastika, D. P., Triyono, J., \& Lestari, U. (2018). Audit dan Implementasi CIS Benchmark Pada Sistem Operasi Linux Debian Server (Studi Kasus: Server Laboratorium Jaringan dan KOmputer 6, Institut Sains \& Teknologi AKPRIND Yogyakarta). Jurnal Jarkom, 6(1), 1-12.

[4] Nazwita, N., \& Ramadhani, S. (2017, May). Analisis Sistem Keamanan Web Server Dan Database Server Menggunakan Suricata. In Seminar Nasional Teknologi Informasi Komunikasi dan Industri (pp. 308-317).

[5] Suhartono, S., \& Patta, A. R. (2017). Sistem Pengamanan Jaringan Admin ServerR Dengan Metode Intrusin Detecton Sysem (IDS) Snort Menggunakan Sistem Operasi ClearOS. Jurnal Teknologi Elekterika, 14(2), 145-155.

[6] Mattetti, M., Shulman-Peleg, A., Allouche, Y., Corradi, A., Dolev, S., \& Foschini, L.. (2015). Security Hardening Of Linux Containers And Their Workloads.

[7] Khurana, S. (2015). A Security Approach to Prevent ARP Poisoning and Defensive Tools. International Journal of Computer and Communication System Engineering, 2(3), 431-437.

[8] Nepal, A. K. Linux Server \& Hardening Security.

[9] Tevault, D. A. (2018). Mastering Linux Security and Hardening: Secure your Linux server and protect it from intruders, malware attacks, and other external threats. Packt Publishing Ltd.

[10] Derby Cardona, D. (2016). Hardening linux processes-extending Grsecurity to integrate system call filters and namespaces (Master's thesis, Uniandes).

[11] Mattetti, M., Allouche, Y., Corradi, A., Dolev, S., \& Foschini, L. Automatic security hardening and protection of linux containers.

[12] Marzuki, I. (2017). Perancangan dan Implementasi Sistem Keamanan Jaringan Komputer Menggunakan Metode Port Knocking Pada Sistem Operasi Linux. JTII (Jurnal Teknologi Informasi Indonesia), 2(2), 18-24.

[13] Mutaqin, A. F. (2016). Rancang Bangun Sistem Monitoring Keamanan Jaringan Prodi Teknik Informatika Melalui SMS Alert dengan Snort. JUSTIN (Jurnal Sistem dan Teknologi Informasi), 4(1), 98-103.

[14] Riska, P., Sugiartawan, P., \& Wiratama, I. (2018). Sistem Keamanan Jaringan Komputer dan Data Dengan Menggunakan Metode Port Knocking. Jurnal Sistem Informasi dan Komputer Terapan Indonesia (JSIKTI), 1(2), 53-64.

[15] Ogasawara, J., \& Kono, K. (2017, December). Nioh: Hardening the hypervisor by filtering illegal I/O requests to virtual devices. In Proceedings of the 33rd Annual Computer Security Applications Conference (pp. 542-552). 